\title{
Chemical induction of the unfolded protein response in the liver increases glucose production and is activated during insulin-induced hypoglycaemia in rats
}

\author{
J. C. Gonzales • C. L. Gentile $\cdot$ K. T. Pfaffenbach • \\ Y. Wei • D. Wang • M. J. Pagliassotti
}

Received: 16 May 2008 / Accepted: 6 June 2008 / Published online: 24 July 2008

(C) Springer-Verlag 2008

\begin{abstract}
Aims/hypothesis Endoplasmic reticulum (ER) stress and the unfolded protein response (UPR) can regulate insulin secretion, insulin action and in vitro hepatocyte glucose release. The aims of this study were to determine whether chemical agents that induce ER stress regulate glucose production in vivo and to identify a physiological setting in which this may be important.

Methods A pancreatic clamp test was performed in anaesthetised rats, and insulin and glucagon were replaced at basal levels. $\left[6,6-{ }^{2} \mathrm{H}_{2}\right]$ Glucose was infused in the absence $(\mathrm{CON}$, $n=10$ ) or presence of ER stress-inducing agents, namely, tunicamycin (Tun, $n=10$ ) or thapsigargin (Thap, $n=10$ ).

Results Arterial insulin, glucagon, corticosterone and NEFA concentrations were constant throughout experiments and not different among groups. After $1 \mathrm{~h}$, the glucose concentration was significantly increased in Tun and Thap rats $(1.5 \pm 0.2$ and $2.1 \pm 0.3 \mathrm{mmol} / \mathrm{l}$, respectively; mean $\pm \mathrm{SD}$ ), but did not change in CON rats. Glucose production increased $(p<0.05)$ by $11.0 \pm$ 1.6 and $13.2 \pm 2.2 \mu \mathrm{mol} \mathrm{kg} \mathrm{min}^{-1}$ in Tun and Thap rats, respectively, but did not change in $\mathrm{CON}$ rats. When glucose
\end{abstract}

Electronic supplementary material The online version of this article (doi:10.1007/s00125-008-1094-9) contains supplementary material, which is available to authorised users.

J. C. Gonzales · C. L. Gentile • K. T. Pfaffenbach · Y. Wei •

D. Wang $\cdot$ M. J. Pagliassotti $(\bowtie)$

Department of Food Science and Human Nutrition,

Colorado State University,

Gifford 234,

Fort Collins, CO 80523-1571, USA

e-mail: pagliasm@cahs.colostate.edu

J. C. Gonzales

Department of Biochemistry and Molecular Biology,

Colorado State University,

Fort Collins, CO, USA was infused in a fourth group (HYPER) to match the increase in glucose observed in the Tun and Thap rats, glucose production decreased by $\sim 22 \mu \mathrm{mol} \mathrm{kg} \mathrm{kg}^{-1} \mathrm{~min}^{-1}$. Liver phosphorylase activity was increased and glycogen decreased in the Tun and Thap groups compared with the CON and HYPER groups. Given that glucose deprivation induces ER stress in cells, we hypothesised that hypoglycaemia, a condition that elicits increased glucose production, would activate the UPR in the liver. Three hour hyperinsulinaemic $\left(5 \mathrm{mU} \mathrm{kg}^{-1} \mathrm{~min}^{-1}\right.$ ) -euglycaemic (EUG, $7.2 \mathrm{mmol} / \mathrm{l}, n=6$ ) or -hypoglycaemic (HYPO, $\sim 2.8 \mathrm{mmol} / 1, n=6$ ) clamps were performed in conscious rats. Several biochemical markers of the UPR were significantly increased in the liver, but not in kidney or pancreas, in HYPO vs EUG rats.

Conclusions/interpretation Based on our findings that the chemical induction of the UPR increased glucose production and that prolonged hypoglycaemia activated the UPR in the liver, we propose that the UPR in the liver may contribute to the regulation of glucose production during prolonged hypoglycaemia.

Keywords Endoplasmic reticulum - Glucose production . Liver

Abbreviations
$\begin{array}{ll}\text { ATF6 } & \text { activating transcription factor-6 } \\ \text { CHOP } & \begin{array}{l}\text { CCAAT/enhancer binding protein homologous } \\ \text { protein }\end{array} \\ \text { CON } & \begin{array}{l}\text { control (saline + DMSO) } \\ \text { change in cycle threshold }\end{array} \\ \Delta \text { CT } & \text { eukaryotic initiation factor-2 } \\ \text { eIF2 } & \text { hyperinsulinaemic--euglycaemic clamp } \\ \text { EUG } & \text { endoplasmic reticulum } \\ \text { ER } & \text { growth arrest and DNA damage-inducible } \\ \text { GADD34 } & \end{array}$




$\begin{array}{ll}\text { G6P } & \text { glucose 6-phosphate } \\ \text { G6Pase } & \begin{array}{l}\text { glucose-6-phosphatase } \\ \text { Hyperglycaemic (glucose + DMSO) }\end{array} \\ \text { HYPO } & \begin{array}{l}\text { hyperinsulinaemic-hypoglycaemic clamp } \\ \text { inositol requiring ER-to-nucleus signalling } \\ \text { IRE1 } \alpha\end{array} \\ \text { protein-1 } \alpha\end{array}$

\section{Introduction}

The endoplasmic reticulum (ER) is integral to the regulation of lipid biosynthesis and protein folding [1]. Disturbances in ER homeostasis, collectively termed ER stress, activate a signalling pathway known as the unfolded protein response (UPR) [2]. Activation of the UPR attenuates protein translation and upregulates the capacity of the ER to fold and degrade proteins [2]. Three ER membraneassociated proteins serve as sensors of ER homeostasis and initiate the UPR: protein kinase-like endoplasmic reticulum eukaryotic initiation factor $2 \alpha$ kinase (PERK), inositol requiring ER-to-nucleus signalling protein- $1 \alpha$ (IRE1 $\alpha$ ) and activating transcription factor-6 (ATF6) [2].

Recent research has linked the UPR with impairments present in diabetes and obesity [3]. For example, targeted disruption of oxygen-regulated protein 150 (ORP150), an ER chaperone that protects cells from ER stress, accelerated the onset of diabetes in Akita mice, whereas an enforced increase of ORP150 reduced insulin resistance $[4,5]$. The UPR, via IRE $1 \alpha$-dependent activation of c-Jun $\mathrm{NH}_{2}$-terminal kinase (JNK), also appears to contribute to obesityinduced insulin resistance in the liver and adipose tissue [3]. PERK-deficient mice display a phenotype characterised by reduced beta cell mass, impaired insulin secretion, and hyperglycaemia [6]. Activation of PERK results in the phosphorylation of eukaryotic initiation factor-2 (eIF2) on serine 51 of the $\alpha$-subunit. When phosphorylation of serine 51 was blocked by a point mutation that changed this residue to alanine, mice died of hypoglycaemia within $18 \mathrm{~h}$ after birth [7]. These deaths were at least partly caused by the lack of expression of gluconeogenic genes in the postnatal mice [7]. We have recently demonstrated that induction of the UPR in primary hepatocytes or H4IIE cells by pharmacological agents (tunicamycin and thapsigargin) increased the capacity for glucose production [8]. This was due, in part, to an increase in levels of glucose-6-phosphatase (G6Pase), a protein responsible for the cleavage of glucose 6-phosphate (G6P) into glucose [9]. Collectively, these studies implicate ER stress and the UPR in insulin signalling and glucose homeostasis.

The aims of the present study were to use an in vivo animal model to further elucidate the link between the UPR and glucose regulation and to identify a relevant physiological setting for the UPR-mediated induction of glucose production. The first experiment involved the infusion of chemical agents that induce ER stress into the portal vein of the rat while performing a pancreatic clamp. A protocol of short duration was chosen for this experiment for two reasons. First, we wanted to obtain multiple liver samples, which meant that the rats had to be under general anesthesia. A short duration $(2 \mathrm{~h}$ ) allowed us to maintain the appropriate depth and consistency of anaesthesia while maintaining body temperature. Second, there is a lack of information on the short-term effects of ER stress. We therefore wanted to determine whether chemical agents that induce ER stress could alter hepatic glucose metabolism over a relatively short time frame. Upon exposure to the agents, glucose production increased rapidly and hyperglycaemia ensued. The increase in glucose production was accompanied by increases in glycogen breakdown and phosphorylase activity in the liver. In the second study we sought to determine whether hypoglycaemia, a setting that elicits an increase in glucose production, activates the UPR in the liver. Results demonstrated that insulin-induced hypoglycaemia in vivo increased multiple biochemical markers of the UPR in the liver, but not in kidney or pancreas.

\section{Methods}

Animals

Male Wistar (Crl:[WI]BR) rats (Charles River, Wilmington, MA, USA) were provided free access to a normal chow diet and water. Rats were housed in pairs in a room in which temperature, humidity and light-dark cycle were controlled. All procedures involving rats were reviewed and approved by the Colorado State University Institutional Animal Care and Use Committee.

\section{Experimental agents}

Tunicamycin (Sigma Chemical, St Louis, MO, USA), which inhibits N-linked protein glycosylation [10], and thapsigargin (Sigma Chemical), a sesquiterpene lactone that inhibits the sarco-/endoplasmic reticulum $\mathrm{Ca}^{2+}$-ATPase [11], were used as ER stress-inducing agents. Tunicamycin and thapsigargin were prepared and solubilised in DMSO. Somatotropin release-inhibiting hormone (Sigma Chemical) 
was used to inhibit pancreatic insulin and glucagon secretion. $\left[6,6-{ }^{2} \mathrm{H}_{2}\right]$ Glucose (Cambridge Isotope Laboratories, Andover, MA, USA) was used to estimate the rates of glucose appearance $\left(R_{\mathrm{a}}\right)$ and disappearance $\left(R_{\mathrm{d}}\right)$.

Surgical and experimental procedures

In Protocol 1, rats (fasted for 4-8 h, weight $234 \pm 58 \mathrm{~g}$ $[$ mean $\pm \mathrm{SD}])$ were anaesthetised using sodium pentobarbital $(25 \mathrm{mg} / \mathrm{kg})$ on the day of the study and catheters were placed in the carotid artery, for blood sampling, and jugular and jejunal veins, for infusions [12].

All experiments were performed on anaesthetised rats, and the body temperature of the rats was maintained using a heating pad. At $-60 \mathrm{~min}$, a primed $(5 \mu \mathrm{mol} / \mathrm{kg})$ continuous $(0.5 \mu \mathrm{mol}$ $\left.\mathrm{kg}^{-1} \mathrm{~min}^{-1}\right)$ infusion of $\left[6,6-{ }^{2} \mathrm{H}_{2}\right]$ glucose was initiated. At $-30 \mathrm{~min}$, somatostatin was infused $\left(1.2 \mathrm{pmol} \mathrm{kg}^{-1} \mathrm{~min}^{-1}\right)$ to inhibit pancreatic insulin and glucagon secretion, and these hormones were replaced at basal levels (insulin at $1 \mathrm{mU} \mathrm{kg}^{-1}$ $\min ^{-1}$ and glucagon at $0.5 \mathrm{ng} \mathrm{kg}^{-1} \mathrm{~min}^{-1}$ ). At $0 \mathrm{~min}$, two baseline blood samples were taken over a period of $10 \mathrm{~min}$ and then either saline + DMSO (CON, $n=10)$, tunicamycin (Tun, $n=10$ ) or thapsigargin (Thap, $n=10$ ) were infused, the latter two at a rate of $0.5 \mu \mathrm{g} \mathrm{kg}^{-1} \mathrm{~min}^{-1}$, into the jejunal vein. This site of delivery was chosen to attempt to selectively deliver these agents to the liver. It is estimated that the rate of Tun and Thap delivery resulted in portal vein concentrations of $200-300 \mathrm{ng} / \mathrm{ml}$, concentrations that elicit an ER stress response in cells in the absence of net cell death [13]. In a fourth group, glucose (+DMSO) was infused to match the increase in glucose observed in the Tun and Thap rats (HYPER, $n=5$ ). This group was added to account for the suppressive effects of glucose on glucose production [14]. Blood samples were also taken immediately prior to starting the pancreatic clamp $(-30 \mathrm{~min})$ and at $15 \mathrm{~min}$ intervals throughout the experiment. A liver sample was taken at $0 \mathrm{~min}$ (Pre) and $60 \mathrm{~min}$ (Post) and a kidney sample was taken at $60 \mathrm{~min}$.

In Protocol 2, catheters were placed in the carotid artery and jugular vein, with the rats under general anaesthesia, at least 5 days prior to experiments $[15,16]$. The rats weighed $325 \pm 60 \mathrm{~g}$ prior to surgery, and had regained at least $95 \%$ of their pre-surgery body weight on the day of study. Experiments were performed on conscious rats that were allowed unrestricted movement. On the day of study, extensions were added to the catheters and rats were allowed to rest for $15 \mathrm{~min}$. A baseline blood sample was taken and a primed continuous (5 mU kg $\left.{ }^{-1} \mathrm{~min}^{-1}\right)$ infusion of insulin was initiated. A glucose infusion was used to maintain plasma glucose levels at either euglycaemic (EUG, $n=6)$ or hypoglycaemic (HYPO, $n=6$ ) levels. In the HYPO group, blood glucose levels were decreased from euglycaemic levels to the hypoglycaemic target level over $60 \mathrm{~min}$, and then maintained at that level for a further $120 \mathrm{~min}$. Blood samples were taken frequently during the first hour and then at $\sim 10-15 \mathrm{~min}$ intervals during the final $2 \mathrm{~h}$. At the end of the experiment, rats were killed with a lethal dose of sodium pentobarbital $(50 \mathrm{mg} / \mathrm{kg})$, and liver, kidney and pancreas samples were removed.

\section{Blood and tissue processing}

Blood samples were centrifuged and the plasma was either used immediately for glucose analysis (Glucose Analyzer; Beckman Instruments, Irvine, CA, USA) or stored at $-80^{\circ} \mathrm{C}$. Tissue samples were processed for western blot analysis, RNA analysis and biochemical assays, as described previously $[8,17,18]$.

\section{Western blot analysis}

Equivalent amounts of protein $(50 \mu \mathrm{g})$ were subjected to SDS-PAGE and transferred to Hybond-P membranes (Amersham Pharmacia Biotech, Piscataway, NJ, USA). Membranes were blocked and incubated with antibodies against total and phosphorylated (serine 51) eIF2 $\alpha$ (Cell Signaling, Danvers, MA, USA), CCAAT/enhancer binding protein homologous protein (CHOP; Sigma Chemical), growth arrest and DNA damage-inducible protein-34 (GADD34; Santa Cruz Biotechnology, Santa Cruz, CA, USA) and actin (Sigma Chemical). Proteins were detected using horseradish peroxidase-conjugated secondary antibodies and a chemiluminescence reagent (Santa Cruz Biotechnology). A UVP Bioimaging system (Upland, CA, USA) was used for detection and analysis of optical density.

\section{RT-PCR}

Superscript II reverse transcriptase and Taq polymerase (Life Technologies, Carlsbad, CA, USA) were used in a two-step protocol for analysis of Xbp1 mRNA [19].

\section{Real-time RT-PCR}

After purified RNA was treated with DNase, reverse transcription was performed using $0.5 \mu \mathrm{g}$ of DNase-treated RNA and Superscript II reverse transcriptase. PCR was performed in 96 well plates, using transcribed cDNA and IQ-SYBR green master mix (Bio-Rad, Hercules, CA, USA). Target genes included those encoding G6Pase (G6pc), phosphoenolpyruvate carboxykinase (Pckl), and the following markers of ER stress: CHOP (Chop, also known as Ddit3), GADD34 (Gadd34) and GRP78 (Tmem132a). Genes encoding $\beta_{2}$-Microglobulin $(B 2 m)$ and cyclophilin (Ppia) were used as housekeeping genes. Details of the primer sets used can be found in previous publications $[8,20]$. 
PCR efficiency was between $90 \%$ and $105 \%$ for primer and probe sets and was linear over five orders of magnitude. Melting curve analysis and gel electrophoresis was used to examine the specificity of products generated for each primer set. Reactions were run in duplicate and the data recorded as the change in cycle threshold $(\triangle \mathrm{CT})$ for the target gene compared with the $\Delta \mathrm{CT}$ for $B 2 m$ [21]. When Ppia was used in place of $B 2 m$, identical results were observed. The $\Delta \mathrm{CT}$ ratio was averaged for control samples, and the fold change calculated as the ratio of individual experimental group samples to this average.

\section{JNK activity}

JNK activity was determined using the N-terminal c-Jun fusion protein bound to glutathione-sepharose beads (Cell Signaling) [12].

\section{G6Pase activity}

G6Pase activity was determined in whole liver homogenates and isolated intact and disrupted liver microsomes at a G6P concentration of $10 \mathrm{mmol} / \mathrm{l}$, as described previously
[22-24]. Values were corrected for non-specific phosphatase activity using paranitrophenylphosphate [25]. The integrity of liver microsomes was assessed using mannose 6-phosphate as the substrate $[17,22,26]$.

Phosphorylase activity

AMP-dependent (total) and AMP-independent phosphorylase activities were determined in liver homogenates using an assay buffer that contained $20 \mathrm{mmol} / \mathrm{l}$ sodium phosphate (pH 7.2), $2 \mathrm{mmol} / 1 \mathrm{MgSO}_{4}, 1.5 \mathrm{mmol} / \mathrm{l} \mathrm{NADP}, 2 \mu \mathrm{g} / \mathrm{ml}$ glucose-6-phosphate dehydrogenase, $3 \mathrm{U} / \mathrm{ml}$ rabbit muscle phosphoglucomutase and $3 \mu \mathrm{mol} / 1$ glucose 1,6-bisphosphate in the absence or presence of $5 \mathrm{mmol} / 15^{\prime}$-AMP. The reaction was initiated by the addition of $10 \mathrm{mg} / \mathrm{ml}$ glycogen and followed over a $2 \mathrm{~h}$ period at $340 \mathrm{~nm}$ using a spectrophotometer (Beckman Instruments) [27].

\section{Glycogen}

Glycogen was degraded using amyloglucosidase and released glucose was analysed using a hexokinase reagent (Sigma Chemical) at $340 \mathrm{~nm}$ using a spectrophotometer. a

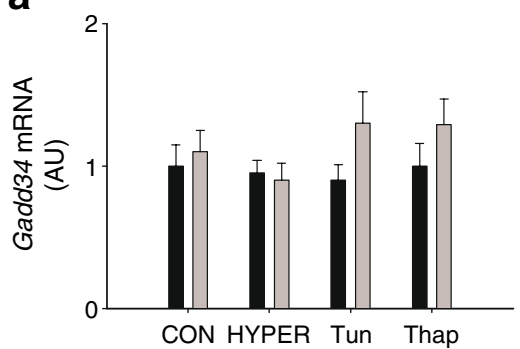

$$
\text { C }
$$
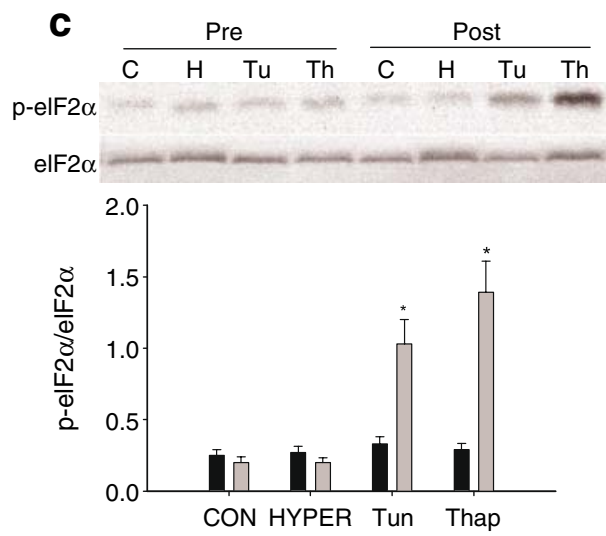

Fig. 1 Markers of UPR activation. Levels of Gadd34 (a) and Chop (b) mRNAs in liver samples taken prior to (Pre, black bars) and following (Post, grey bars) the intraportal infusions in the CON (or C), HYPER (or H), Tun (or Tu) or Thap (or Th) groups of anaesthetised rats. c Phosphorylated (p-) and total eIF $2 \alpha$ in liver samples taken prior to and following the intraportal infusions. Data are reported as the mean \pm SD for $n=5-10$ rats per group. A representative gel of p-eIF $2 \alpha$ b

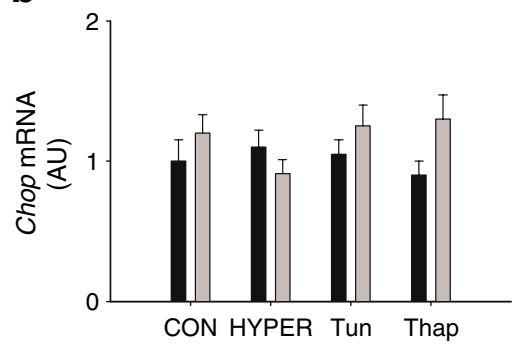

d

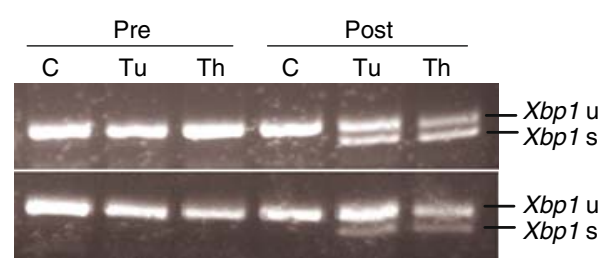

e

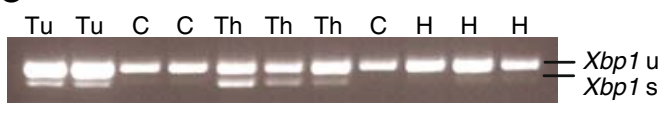

and total eIF $2 \alpha(\operatorname{eIF} 2 \alpha)$ is shown. ${ }^{*} p<0.05$ vs all other groups. d Unspliced (u) and spliced (s) Xbpl mRNA in liver samples taken prior to and following the intraportal infusions in the different groups. A representative gel is provided from a total $n=10$ rats per group. e Unspliced and spliced Xbpl mRNA in liver samples following the intraportal infusions. A representative gel is provided from a total $n=$ 5-10 rats per group. AU, arbitrary units 


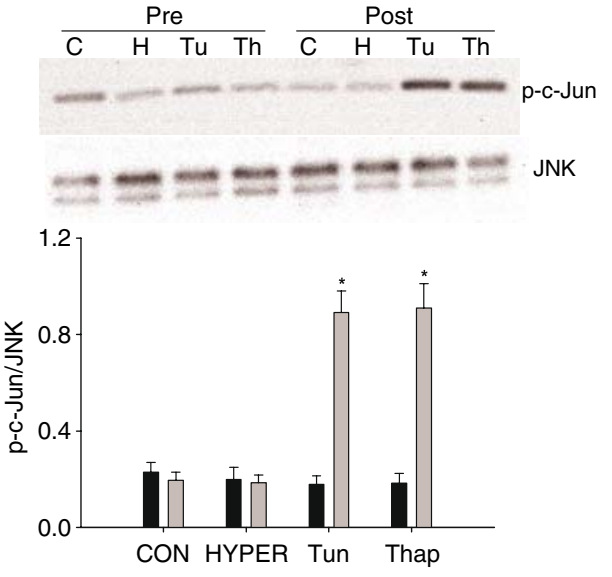

Fig. 2 JNK activity in liver samples taken prior to (Pre) and following (Post) the intraportal infusions in the CON (or C), HYPER (or H), Tun (or Tu) or Thap (or Th) groups of anaesthetised rats. Data are reported as the mean \pm SD for $n=5-10$ rats per group. ${ }^{*} p<0.05$ different from all other groups. A representative gel is provided for phosphorylated (p-) c-Jun and JNK

Plasma metabolite and hormone analyses

Glucagon and insulin levels were determined using kits from Linco Research (St Charles, MO, USA), corticosterone levels were determined by radioimmunoassay (ICN Biochemicals, Costa Mesa, CA, USA) and NEFA levels were assessed using the NEFA-C kit (Wako Chemicals, Richmond, VA, USA). Plasma glucose was measured using an automated analyser (Beckman Instruments).
Isotope analysis

Glucose isotope enrichment and concentration were measured by gas chromatography-mass spectrometry (Agilent, Palo Alto, CA, USA). Detailed methods and calculations are provided in the Electronic supplementary material (ESM). Endogenous rates of appearance are presented for all groups.

\section{Calculations}

Microsomal membrane integrity is reported as the per cent latency: $100-(100 \times$ [mannose-6-phosphatase activity in intact microsomes/mannose-6-phosphatase activity in disrupted microsomes]) [22, 26].

Data analysis and statistics

Data were analysed using the paired Student's $t$ test, ANOVA or repeated measures ANOVA. Where appropriate, post hoc comparisons among means were performed using the Scheffé or Tukey tests. Significance was chosen at $p<0.05$. All data are presented as mean $\pm \mathrm{SD}$.

\section{Results}

Protocol 1. Pancreatic clamp experiments on anaesthetised rats

Markers of UPR activation In the liver, levels of Chop and Gadd34 mRNAs were not increased in any of the groups
Fig. 3 Plasma parameters. Plasma insulin (a), glucagon (b), corticosterone (c) and NEFA (d) prior to $(-30$ and $0 \mathrm{~min})$ and during (15-60 $\mathrm{min})$ the intraportal infusions in the CON (black circles), HYPER (stars), Tun (white circles) or Thap (triangles) groups of anaesthetised rats. The vertical dashed lines denote the start of the infusions. Data are reported as the mean \pm SD for $n=5-10$ per group a

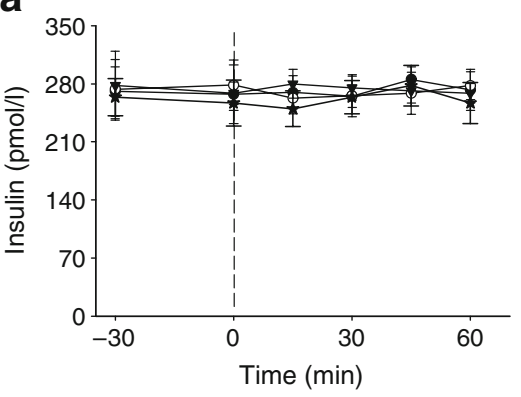

C

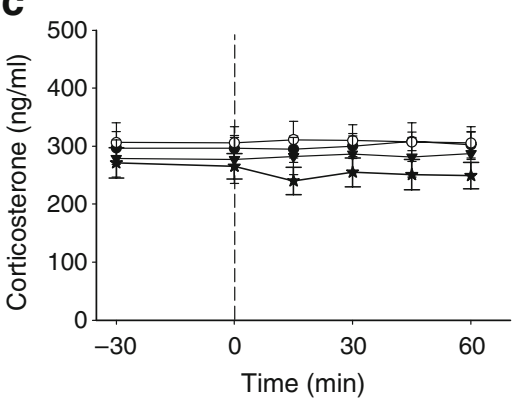

b

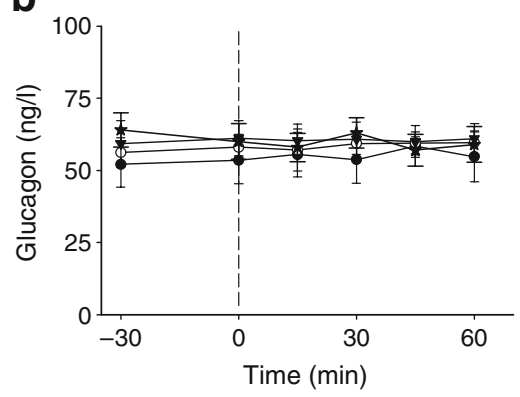

d

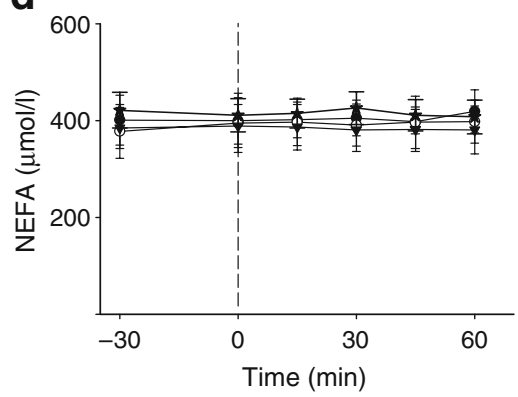


over the course of the experiment (Fig. 1a,b). Tmem $132 a$ mRNA was not increased in any of the groups over the course of the experiment (ESM Fig. 1a). Phosphorylation of eIF2 $\alpha$ was increased in Tun and Thap rats but not CON or HYPER rats (Fig. 1c). In the kidney, phosphorylation of eIF2 $\alpha$ was not significantly different among groups (ESM Fig. 1b). Xbp1 mRNA splicing was observed in Tun and Thap rats but not CON or HYPER rats (Fig. 1d,e).

Activation of UPR-associated stress signalling pathways JNK activity has been linked to the proximal UPR sensor protein IRE1 $\alpha$ [28]. Therefore, to further assess the effects of tunicamycin and thapsigargin infusions on UPR-related activation, we measured JNK activity. JNK activity was increased in Tun and Thap rats compared with CON and HYPER rats (Fig. 2).

Plasma hormones and NEFA Plasma insulin, glucagon, corticosterone and NEFA concentrations did not change throughout the experiment in any group, and there were no significant differences among groups at any time-point (Fig. 3).

Plasma glucose and glucose kinetics Plasma glucose levels were significantly increased in Tun, Thap and HYPER rats compared with those in CON rats (Fig. 4a,b). The $R_{\mathrm{a}}$ for
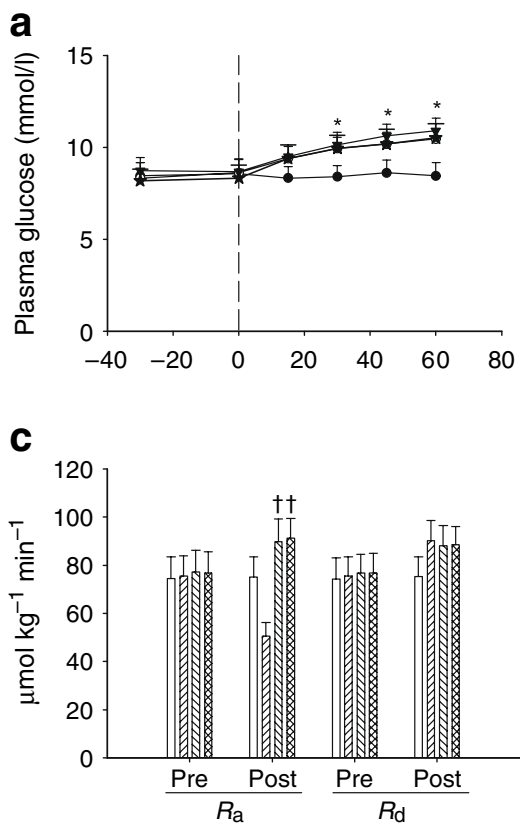

Fig. 4 Plasma glucose and glucose kinetics. a Plasma glucose prior to $(-30$ and $0 \mathrm{~min})$ and during $(15-60 \mathrm{~min})$ the intraportal infusions in the CON, HYPER, Tun and Thap groups of anaesthetised rats. The vertical dashed lines denote the start of the infusions. $\mathbf{b}$ The change in plasma glucose concentration between 0 and $60 \mathrm{~min}$. $\mathrm{c} R_{\mathrm{a}}$ and $R_{\mathrm{d}}$ for glucose prior to (Pre) and following (Post) the intraportal infusions in glucose was significantly increased in Tun and Thap rats compared with that in HYPER rats, and the change in $R \mathrm{a}$ (Post-Pre) was significantly increased in Tun and Thap rats compared with that in CON and HYPER rats (Fig. $4 \mathrm{c}, \mathrm{d}$ ). In contrast, $R_{\mathrm{d}}$ was not significantly increased in Tun and Thap rats compared with that in HYPER rats, and the change in $R_{\mathrm{d}}$ (Post-Pre) was significantly increased in HYPER, Tun and Thap rats compared with that in CON rats (Fig. 4c,d).

Liver glycogen and phosphorylase activity The glycogen concentration of the liver ( $\mu \mathrm{mol} / \mathrm{g}$ liver) following infusions was significantly lower in the Tun and Thap groups compared with that in the CON and HYPER groups (Fig. 5a). The change in liver glycogen levels was also significantly greater in Tun and Thap groups compared with those in the CON and HYPER groups (Fig. 5a). AMPindependent liver phosphorylase activity following infusions was significantly higher in the Tun and Thap rats than in the CON and HYPER rats (Fig. 5b). The change in phosphorylase activity was also significantly greater in the Tun and Thap rats than in the CON and HYPER rats (Fig. 5b). AMP-dependent phosphorylase activity (total activity) was not significantly different among the four groups (Fig. 5c).
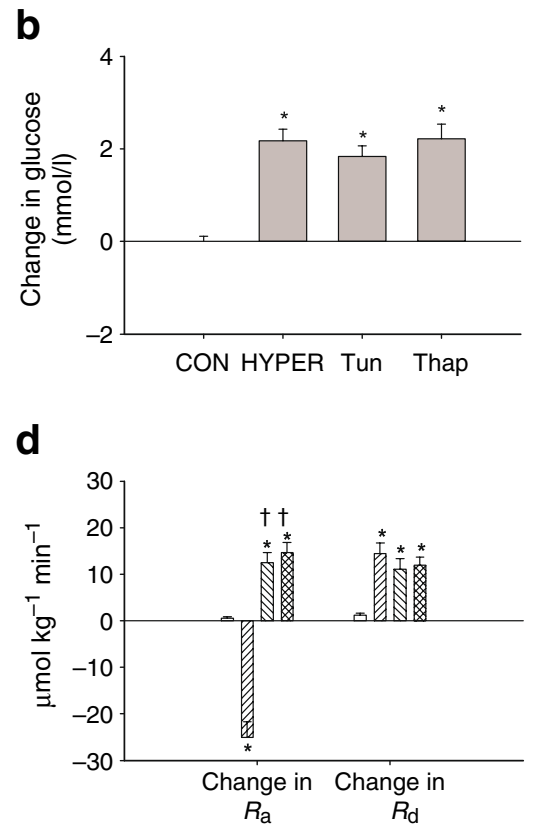

the CON (open bars), HYPER (right hatched bars), Tun (left hatched bars) and Thap (double hatched bars) groups. Pre was calculated from two samples taken at -10 and 0 min. Post was calculated from two samples taken at 45 and $60 \mathrm{~min}$. d The change in the glucose $R_{\mathrm{a}}$ and $R_{\mathrm{d}}$ between 0 and $60 \mathrm{~min}$. Data are reported as the mean $\pm \mathrm{SD}$ for $n=$ $5-10$ per group. ${ }^{*} p<0.05$ vs $\mathrm{CON},{ }^{\dagger} p<0.05$ vs HYPER 

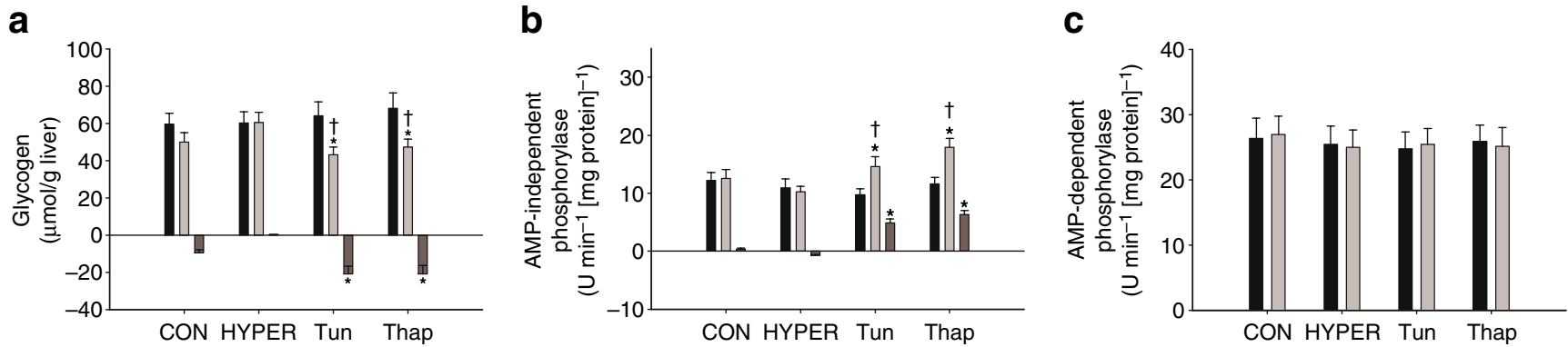

Fig. 5 Liver glycogen concentration (a) and phosphorylase activity (b, c) prior to (Pre, black bars) and following (Post, light grey bars) the intraportal infusions in the CON, HYPER, Tun or Thap groups of anaesthetised rats. Change (dark grey bars) represents the difference between post and pre samples. Data are reported as the mean \pm SD for $n=5-10$ per group. ${ }^{*} p<0.05$ vs $\mathrm{CON}$ and HYPER, ${ }^{\dagger} p<0.05$ vs corresponding Pre value
G6Pase and phosphoenolpyruvate carboxykinase Levels of $G 6 p c$ and Pckl mRNAs were not significantly increased over the course of the experiment and were not different among groups (data not shown). G6Pase activity prior to or following infusions was not significantly different among groups (Fig. 6a,b). Although the change in G6Pase activity was significantly increased in Tun and Thap rats compared with that in the CON and HYPER rats, this represented a small fraction of the total activity measured (Fig. 6a,b). The per cent latency of microsomes was not significantly different among groups and averaged $>87 \%$.

Protocol 2. Euglycaemic and hypoglycaemic clamps in conscious rats

Plasma glucose and hormones Plasma glucose levels were significantly reduced and glucagon and corticosterone levels were significantly increased in HYPO rats relative to those in EUG rats (Fig. $7 \mathrm{a}-\mathrm{c}$ ).

Markers of UPR activation In the liver, levels of Chop, Gadd34 and Tmem132a mRNAs were significantly increased in HYPO rats compared with those in EUG rats (Fig. 8a). Spliced Xbpl mRNA was observed in HYPO rats but not in EUG rats (Fig. 8b). In addition, levels of CHOP and GADD34 protein were significantly increased in HYPO rats compared with those in EUG rats (Fig. 8c). Levels of GRP78 protein were not significantly different between HYPO and EUG rats (data not shown). In the kidney and pancreas, levels of Chop, Gadd 34 and Tmem $132 a$ mRNAs and the corresponding proteins were not significantly different between groups (ESM Fig. 2). Liver JNK activity was not significantly different between the EUG and HYPO rats (data not shown).

Liver phosphorylase activity AMP-independent phosphorylase activity was $9.7 \pm 1.1 \mathrm{U} \mathrm{min}^{-1}[\mathrm{mg} \text { protein }]^{-1}$ in EUG rats and $16.5 \pm 1.9 \mathrm{U} \mathrm{min}^{-1}[\mathrm{mg} \text { protein }]^{-1}$ in HYPO rats $(p<0.05)$. AMP-independent phosphorylase activity was $27.2 \pm 3.3$ in EUG rats and $29.1 \pm 3.1 \mathrm{U} \mathrm{min}^{-1}[\mathrm{mg} \text { protein }]^{-1}$ in HYPO rats.

G6pc expression and G6Pase activity Levels of G6pc mRNA were not different between the EUG and HYPO
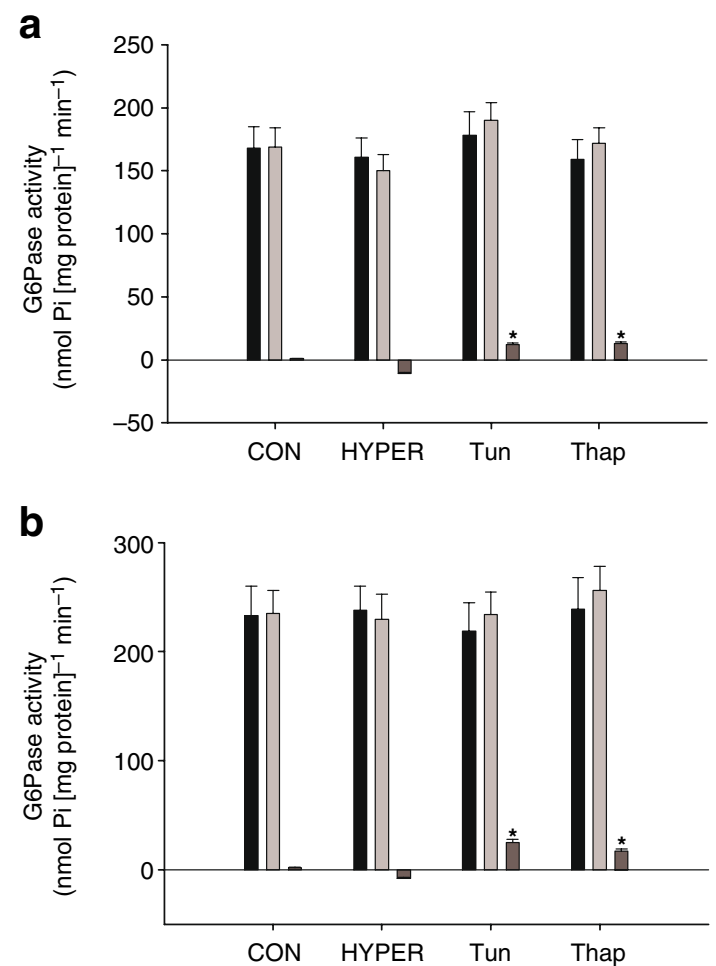

Fig. 6 G6Pase activity in whole liver homogenates (a) and intact liver microsomes (b) prior to (Pre, black bars) and following (Post, light grey bars) the intraportal infusions in the CON, HYPER, Tun and Thap groups of anaesthetised rats. Change (dark grey bars) represents the difference between post and pre samples. Data are reported as the mean \pm SD for $n=5-10$ per group. ${ }^{*} p<0.05$ vs CON and HYPER. Pi, inorganic phosphate 

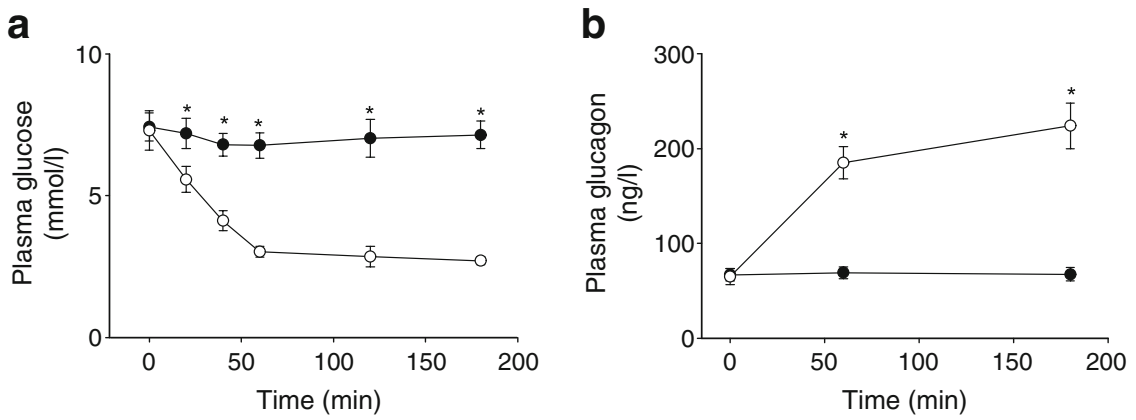

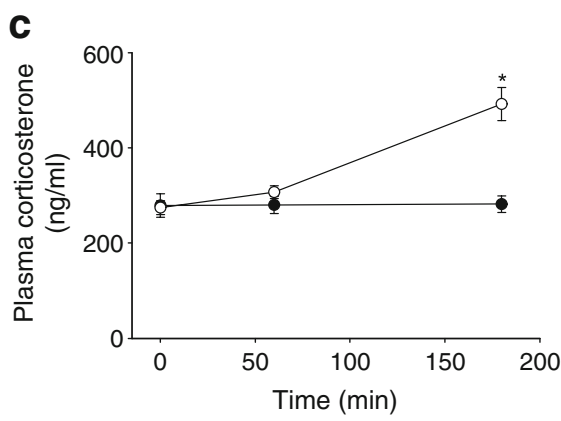

Fig. 7 Plasma parameters. Plasma glucose (a), glucagon (b) and corticosterone (c) concentrations in the EUG (black circles) and
HYPO (white circles) groups of conscious rats. Data are reported as the mean \pm SD for $n=6$ per group. ${ }^{*} p<0.05$ vs EUG

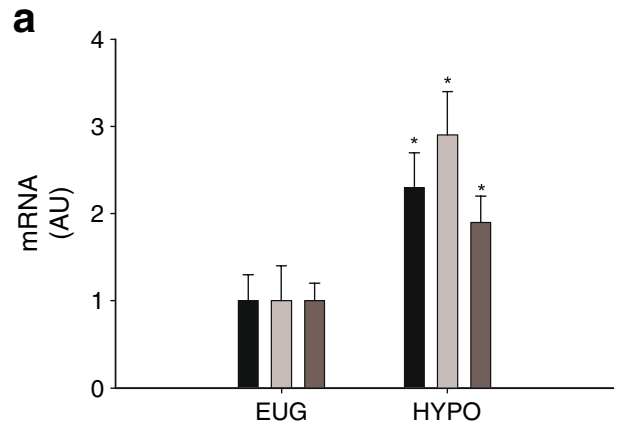

b

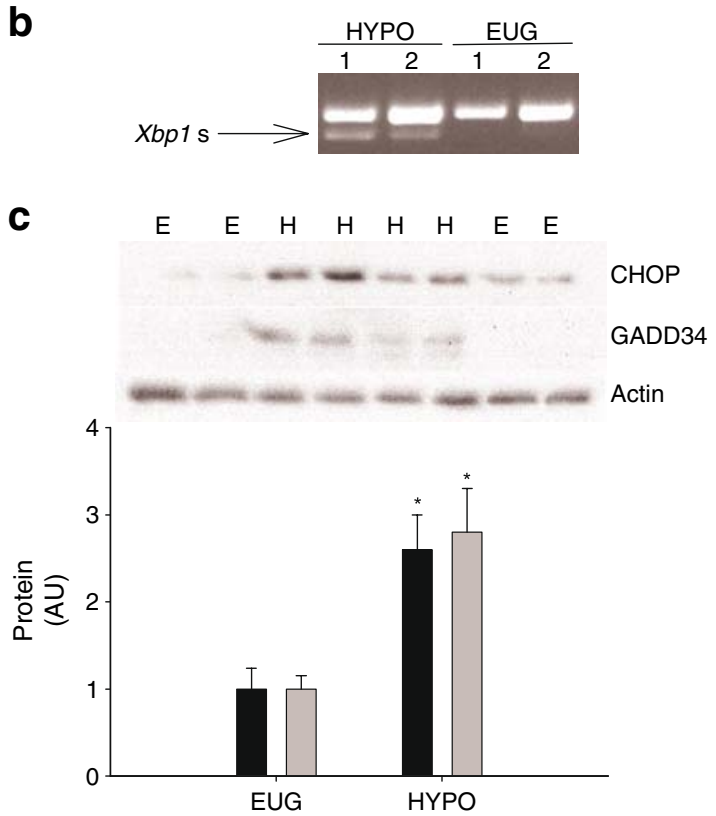

Fig. 8 UPR markers. a Levels of Chop (black bars), Gadd34 (light grey bars) and Tmem132a (dark grey bars) mRNAs in liver samples taken following the clamps in the EUG (or E) and HYPO (or H) groups of conscious rats. b Representative gel of spliced Xbpl mRNA $(X b p l \mathrm{~s})$ in liver samples taken following clamps. Xbpl s was observed in five of six rats in the HYPO group and none of six rats in the EUG group. c CHOP and GADD34 in liver samples taken following clamps. The representative gel shows CHOP, GADD34 and actin (loading control). Data in the graph are reported as the mean $\pm \mathrm{SD}$ for $n=6$ per group. ${ }^{*} p<0.05$ vs EUG. AU, arbitrary units groups. However G6Pase activity in liver homogenates was $189 \pm 22 \mathrm{nmol}[\mathrm{g} \mathrm{liver}]^{-1} \mathrm{~min}^{-1}$ in EUG rats and $251 \pm$ $29 \mathrm{nmol}[\mathrm{g} \text { liver }]^{-1} \mathrm{~min}^{-1}$ in HYPO rats $(p<0.05)$.

\section{Discussion}

The present study examined whether the UPR plays a role in the regulation of glucose production in vivo, and sought to identify a physiological setting in which this might be relevant. The results demonstrate that the intraportal infusion of tunicamycin or thapsigargin induced ER stress in the liver and increased glucose production, net liver glycogen breakdown and liver phosphorylase activity. Furthermore, components of the UPR were activated in the liver, but not pancreas or kidney, and liver phosphorylase activity was increased following prolonged, insulininduced hypoglycaemia. Therefore, we hypothesise that activation of the UPR in the liver may contribute to the counter-regulatory response to hypoglycaemia via regulation of glucose production.

ER stress and UPR activation occur in response to glucose deprivation, infection by hepatitis $\mathrm{C}$, obesity and diabetes, all of which are associated with alterations in the regulation of glucose production [2, 29-31]. In the present study, the intraportal infusion of chemical agents that induce the UPR increased glucose production resulting in an imbalance between glucose production and utilisation. The increase in glucose production was observed in the absence of changes in insulin, glucagon, NEFA or corticosterone. Taken together with the results of a previous study demonstrating that these chemical agents increased glucose release in isolated hepatocytes, these data suggest that the UPR can regulate liver glucose production via direct mechanisms [8].

Activation of glycogenolysis supports rapid changes in glucose production and is a first-line cellular response to changes in glucose delivery and energy demand [32, 33]. A 
previous study, performed in dermal fibroblasts, demonstrated that chemical induction of the UPR rapidly activated glycogen phosphorylase [9]. In the present study, liver glycogen concentrations were significantly reduced and phosphorylase activity was increased when tunicamycin or thapsigargin was infused into the portal venous system. Collectively, these results suggest that short-term, chemically induced activation of the UPR in the liver increases glucose production via mechanisms that involve increased glycogenolysis. The mechanisms that link the UPR with glycogenolysis are presently unclear, but could involve cAMP- and/or calcium-mediated signalling [34-36].

G6Pase is an ER membrane-associated protein complex, and transport of G6P into the lumen of the ER is necessary for interface with the catalytic subunit of the protein complex $[9,37,38]$. In a previous study, higher concentrations of tunicamycin and thapsigargin and more prolonged exposure resulted in the upregulation of $G 6 p c$ expression and increased G6Pase protein content in primary hepatocytes [8]. In the present study, the intraportal infusion of tunicamycin or thapsigargin induced a significant increase in G6Pase activity in whole liver homogenates and microsomes. However, the magnitude of this increase was small relative to the total activity measured. In addition, statistical comparison of the absolute values of G6Pase activity was not different among groups. Thus, it would appear that short-term activation of the UPR does not produce large changes in the activity of the G6Pase enzyme complex. However, it can be speculated that small changes in G6Pase activity coupled with an increase in the supply of G6P from glycogenolysis may account for the observed increases in glucose production and glucose concentration.

It has been suggested that PERK-mediated phosphorylation of eIF $2 \alpha$ represents one of the earliest responses to ER stress $[39,40]$. Phosphorylation of eIF $2 \alpha$ was observed in the liver, but not kidney, in response to the infusion of chemical agents that induced ER stress into the portal vein. In addition, we demonstrate that these agents also resulted in Xbpl mRNA splicing and increased phosphorylation of JNK, both of which are linked to IRE1 $\alpha$ activation $[41,42]$. It is likely that the lack of change in gene markers of UPR activation, such as Chop, Gadd34 and Tmem132a mRNA, was due to the short duration of the experimental protocol $[8,39]$. These data suggest that the infusion of these agents not only activated components of the UPR, but that this activation was localised to the liver.

Glucose deprivation induces ER stress and activates the UPR in a number of cell types [42-45]. Since a rapid increase in glucose production accompanies insulin-induced hypoglycaemia [46, 47], we reasoned that hypoglycaemia may be a setting in which UPR-mediated regulation of glucose production is physiologically relevant. Follow- ing $3 \mathrm{~h}$ hyperinsulinaemic-hypoglycaemic clamps, several gene and protein markers of UPR activation were increased in the liver, but not in kidney or pancreas. In addition, G6Pase and phosphorylase activity were significantly increased in liver homogenates from rats that underwent hypoglycaemic clamps. Adrenaline (epinephrine) and noradrenaline (norepinephrine) are critical counter-regulatory hormones, and it has been demonstrated that noradrenaline can induce ER stress and activate the UPR in PC12 cells [48]. It is also possible that changes in energy and/or redox status or calcium homeostasis during hypoglycaemia may influence ER function. Future work will examine the role of these hormones and hypoglycaemia per se in the regulation of the UPR in the liver and will determine whether the UPR can directly regulate glucose production and glycogenolysis.

In summary, the intraportal infusion of chemical agents that activate the UPR increased glucose production and hepatic phosphorylase activity and reduced liver glycogen levels in vivo. Prolonged insulin-induced hypoglycaemia activated the UPR, phosphorylase and G6Pase in the liver. Although the present study does not demonstrate a causal link between activation of the UPR and glucose production, it does provide the first evidence that the UPR is activated in the liver in response to prolonged hypoglycaemia in vivo. Therefore, these data may have implications for understanding the complex regulation of liver glucose metabolism during hypoglycaemia.

Acknowledgements This work was supported by National Institutes of Health (grant numbers DK47416 and DK072017) and the Lillian Fountain Smith Endowment.

Duality of interest The authors declare that there is no duality of interest associated with this manuscript.

\section{References}

1. Nunnari J, Walter P (1996) Regulation of organelle biogenesis. Cell 84:389-394

2. Kaufman RJ (2002) Orchestrating the unfolded protein response in health and disease. J Clin Invest 110:1389-1398

3. Ozcan U, Cao Q, Yilmaz E et al (2004) Endoplasmic reticulum stress links obesity, insulin action and type 2 diabetes. Science 306:457-461

4. Nakatani Y, Kaneto H, Kawamori D et al (2005) Involvement of endoplasmic reticulum stress in insulin resistance and diabetes. J Biol Chem 280:847-851

5. Ozawa K, Miyazaki M, Matsuhisa M et al (2005) The endoplasmic reticulum chaperone improves insulin resistance in type 2 diabetes. Diabetes 54:657-663

6. Harding HP, Zeng H, Zhang Y et al (2001) Diabetes mellitus and exocrine pancreatic dysfunction in Perk-/- mice reveals a role for translational control in secretory cell survival. Mol Cell 7:11531163 
7. Scheuner D, Song B, McEwen E et al (2001) Translational control is required for the unfolded protein response and in vivo glucose homeostasis. Mol Cell 7:1165-1176

8. Wang D, Wei Y, Schmoll D, Maclean KN, Pagliassotti MJ (2006) Endoplasmic reticulum stress increases glucose-6-phosphatase and glucose cycling in liver cells. Endocrinology 147:350-358

9. Nordlie RC, Foster JD, Lange AJ (1999) Regulation of glucose production by the liver. Annu Rev Nutr 19:379-406

10. Shang J, Korner C, Freeze H, Lehrman MA (2002) Extension of lipid-linked oligosaccharides is a high-priority aspect of the unfolded protein response: endoplasmic reticulum stress in type I congenital disorder of glycosylation fibroblasts. Glycobiology 12:307-317

11. Thastrup O, Cullen PJ, Drobak BK, Hanley MR, Dawson AP (1990) Thapsigargin, a tumor promoter, discharges intracellular calcium stores by specific inhibition of the endoplasmic reticulum calcium ATPase. Proc Natl Acad Sci U S A 87:2466-2470

12. Wei Y, Pagliassotti MJ (2004) Hepatospecific effects of fructose on c-jun $\mathrm{NH}_{2}$-terminal kinase: implications for hepatic insulin resistance. Am J Physiol Endocrinol Metab 287:E926-E933

13. Rutkowski DT, Arnold SM, Miller CN et al (2006) Adaptation to ER stress is mediated by differential stabilities of pro-survival and pro-apoptotic mRNAs and proteins. PLoS Biol 4:2024-2041

14. Camacho RC, Lacy DB, James FD, Coker RH, Wasserman DH (2004) Hepatic glucose autoregulation: responses to small, noninsulin-induced changes in arterial glucose. Am J Physiol Endocrinol Metab 287:E269-E274

15. Pagliassotti MJ, Prach PA, Koppenhafer TA, Pan DA (1996) Changes in insulin action, triglycerides, and lipid composition during sucrose feeding in rats. Am J Physiol 271:R1319-R1326

16. Popovic V, Popovic P (1960) Permanent cannulation of aorta and vena cava in rats and ground squirrels. J Appl Physiol 15:727728

17. Pagliassotti MJ, Wei Y, Bizeau ME (2003) Glucose-6-phosphatase activity is not suppressed but the mRNA level is increased by a sucrose-enriched meal in rats. J Nutr 133:32-37

18. Pagliassotti MJ, Kang J, Thresher JS, Sung CK, Bizeau ME (2002) Elevated basal PI 3-kinase activity and reduced insulin signaling in sucrose-induced hepatic insulin resistance. Am J Physiol Endocrinol Metab 282:E170-E176

19. Wang D, Wei Y, Pagliassotti MJ (2006) Saturated fatty acids promote endoplasmic reticulum stress and liver injury in rats with hepatic steatosis. Endocrinology 147:943-951

20. Wei Y, Wang D, Topczewski F, Pagliassotti MJ (2006) Saturated fatty acids induce endoplasmic reticulum stress and apoptosis independently of ceramide in liver cells. Am J Physiol Endocrinol Metab 291:E275-E281

21. Muller PY, Janovjak H, Miserez AR, Dobbie Z (2002) Processing of gene expression data generated by quantitative real-time RTPCR. BioTechniques 32:1372-1379

22. Commerford SR, Ferniza JB, Bizeau ME, Thresher JS, Willis WT, Pagliassotti MJ (2002) Diets enriched in sucrose or fat increase gluconeogenesis and G-6-Pase but not basal glucose production in rats. Am J Physiol Endocrinol Metab 283:E545-E555

23. Jorgenson RA, Nordlie RC (1980) Multifunctional glucose-6phosphatase studied in permeable isolated hepatocytes. J Biol Chem 255:5907-5915

24. Mithieux G, Daniele N, Payrastre B, Zitoun C (1998) Liver microsomal glucose-6-phosphatase is competitively inhibited by the lipid products of phosphatidylinositol 3-kinase. J Biol Chem 273:17-19

25. Minassian C, Daniele N, Bordet JC, Zitoun C, Mithieux G (1995) Liver glucose-6-phosphatase activity is inhibited by refeeding in rats. J Nutr 125:2727-2732

26. Arion WJ, Walls HE (1982) The importance of membrane integrity in kinetic characterizations of the microsomal glucose6-phosphatase system. J Biol Chem 257:11217-11220
27. Gill A, Gao N, Lehrman MA (2002) Rapid activation of glycogen phosphorylase by the endoplasmic reticulum unfolded protein response. J Biol Chem 277:44747-44753

28. Urano F, Wang X, Bertolotti A et al (2000) Coupling of stress in the ER to activation of JNK protein kinases by transmembrane protein kinase IRE1. Science 287:664-666

29. Bougneres P-F, Artavia-Loria E, Henry S, Basdevant A, Castano L (1989) Increased basal glucose production and utilization in children with recent obesity versus adults with long-term obesity. Diabetes 38:477-483

30. Mendez-Sanchez N, Chavez-Tapia NC, Zamora-Valdes D, MedinaSantillan R, Uribe M (2007) Hepatobiliary diseases and insulin resistance. Curr Med Chem 14:1988-1999

31. Parekh S, Anania FA (2007) Abnormal lipid and glucose metabolism in obesity: Implications for nonalcoholic fatty liver disease. Gastroenterology 132:2191-2207

32. Cherrington AD (1999) Control of glucose uptake and release by the liver in vivo. Diabetes 48:1198-1214

33. Kjaer M (1998) Hepatic glucose production during exercise. Adv Exp Med Biol 441:117-127

34. Salas VM, Corcoran GB (1997) Calcium-dependent DNA damage and adenosine 3 ', $5^{\prime}$-cyclic monophosphate-independent glycogen phosphorylase activation in an in vitro model of acetaminopheninduced liver injury. Hepatology 25:1432-1438

35. Ruf J, Gella FJ (1990) Role of calcium and cyclic AMP on the activation of lymphocyte glycogen phosphorylase by mitogens. Int J Biochem 22:341-345

36. Burdakov D, Petersen OH, Verkhratsky A (2005) Intraluminal calcium as a primary regulator of endoplasmic reticulum function. Cell Calcium 38:303-310

37. van Schaftingen E, Gerin I (2002) The glucose-6-phosphatase system. Biochem J 362:513-532

38. Mithieux G (1997) New knowledge regarding glucose-6-phosphatase gene and protein and their roles in the regulation of glucose metabolism. Eur J Endocrinol 136:137-145

39. Rutkowski DT, Kaufman RJ (2004) A trip to the ER: coping with stress. Trends Cell Biol 14:20-28

40. Wek RC, Jiang HY, Anthony TG (2006) Coping with stress: eIF2 kinases and translational control. Biochem Soc Trans 34:7-11

41. Hotamisligil GS (2005) Role of endoplasmic reticulum stress and c-Jun $\mathrm{NH}_{2}$-terminal kinase pathways in inflammation and origin of obesity and diabetes. Diabetes 54(Suppl 2):S73-S78

42. Kaufman RJ (1999) Stress signaling from the lumen of the endoplasmic reticulum: coordination of gene transcriptional and translational controls. Genes Dev 13:1211-1233

43. Ikesugi K, Mulhern ML, Madson CJ et al (2006) Induction of endoplasmic reticulum stress in retinal pericytes by glucose deprivation. Curr Eye Res 31:947-953

44. Rao RV, Niazi K, Mollahan P et al (2006) Coupling endoplasmic reticulum stress to the cell-death program: a novel HSP90independent role for the small chaperone protein p23. Cell Death Differ 13:415-425

45. Nadanaka S, Yoshida H, Mori K (2006) Reduction of disulfide bridges in the lumenal domain of ATF6 in response to glucose starvation. Cell Struct Funct 31:127-134

46. Bolli GB, Fanelli CG (1999) Physiology of glucose counterregulation to hypoglycemia. Endocrinol Metab Clin North Am 28:467-493

47. Kishore P, Gabriely I, Cui MH et al (2006) Role of hepatic glycogen breakdown in defective counterregulation of hypoglycemia in intensively treated type 1 diabetes. Diabetes 55:659-666

48. Mao W, Iwai C, Keng PC, Vulapalli R, Liang CS (2006) Norepinephrine-induced oxidative stress causes PC12 cell apoptosis by both endoplasmic reticulum stress and mitochondrial intrinsic pathway: inhibition of phosphatidylinositol 3-kinase survival pathway. Am J Physiol Cell Physiol 290:C1373-C1384 